Bài báo khoa học

\title{
Phương pháp hiệu chỉnh dự báo quỹ đạo bão từ sản phẩm hệ thống dự báo tổ hợp thông qua lựa chọn thành phần tổ hợp tối ưu
}

\author{
Trần Quang Năng ${ }^{*}$, Trần Tân Tiến ${ }^{2}$
}

\author{
${ }^{1}$ Trung tâm Dự báo khí tượng thủy văn quốc gia \\ ${ }^{2}$ Trường Đại học khoa học tự nhiên Hà Nội; tientt49@gmail.com \\ * Tác giả liên hệ: trannang030984@gmail.com; Tel.: +84-936328136
}

Ban Biên tập nhận bài: 12/7/2020; Ngày phản biện xong: 25/8/2020; Ngày đăng bài: 25 $/ 10 / 2020$

Tóm tắt: Một trong những sản phẩm dự báo quỹ đạo bão từ hệ thống dự báo tổ hợp là dự báo quỹ đạo bão được tính từ trung bình quỹ đạo dự báo của các thành phần tổ hợp. Tuy nhiên, khi đánh giá nhanh sai số hạn 6-12 giờ với các vị trí tâm bão phân tích từ số liệu vệ tinh, số liệu gió bề mặt biển (được xem như là các quan trắc quỹ đạo bão chuẩn tạm thời trong thời gian thực), sẽ tồn tại một số lượng thành phần tổ hợp có sai số thấp hơn so với sai số trung bình nhiều năm của trung bình tổ hợp. Do đó việc lấy trung bình có trọng số các thành phần này (selective ensemble member) có khả năng cho phép bổ sung, cập nhật được các thông tin về sai số dự báo. Dựa trên nguyên lý này, bài báo sẽ trình bày tổng quan và phương pháp trung bình tổ hợp có lựa chọn cho dự báo quỹ đạo bão dựa trên sai số của các thành phần hệ thống dự báo tồ hợp (EPS) tại các thời hạn dự báo ngắn (6-12 giờ), đề xuất bởi Qi và cộng sự năm 2014. Bài báo trình bày một số thử nghiệm ban đầu được áp dụng trong trường hợp dự báo cơn bão số 12 (Damrey) năm 2017 từ các sản phẩm dự báo tổ hợp bao gồm 51 thành phần của Trung tâm Dự báo thời tiết hạn vừa Châu Âu (ECMWF).

Từ khóa: Dự báo tổ hợp; Hiệu chỉnh dự báo quỹ đạo; Lựa chọn thành phần tổ hợp tối ưu.

\section{1. Đặt vấn đề}

Hiện nay, một trong những phương pháp chủ đạo được sử dụng trong công tác dự báo bão là ứng dụng tham khảo các sản phẩm dự báo từ các mô hình dự báo thời tiết số trị (NWP) ở quy mô toàn cầu và khu vực. Trong nghiệp vụ dự báo bão, bên cạnh việc cung cấp các sản phẩm dự báo trường, các mô hình NWP còn cung cấp các sản phẩm dự báo quỹ đạo và cường độ bão. Tại Việt Nam có rất nhiều công trình đã ứng dụng mô hình NWP toàn cầu hoặc khu vực trong dự báo quỹ đạo và cường độ bão ở Việt Nam [1-6]. Mặc dù khả năng ứng dụng của các mô hình NWP nói riêng và hệ thống dự báo tổ hợp (Ensemble Prediction System$E P S$ ) trong dự báo quỹ đạo hoặc cường độ bão trên khu vực Biển Đông Việt Nam khá cao, tuy nhiên các kết quả đánh giá cũng cho thấy hầu hết các mô hình và hệ thống dự báo tổ hợp vẫn tồn tại những sai số hệ thống nhất định trong dự báo quỹ đạo.

Hai cách tiếp cận để cải tiến chất lượng dự báo bão cho các mô hình NWP bao gồm hướng tiếp cận này liên quan đến cơ chế động lực của bão và tính bất định trong mô hình NWP và hướng xử lý kết quả hậu mô hình. Ở hướng thứ nhất có thể minh họa thông qua các nghiên cứu như việc áp dụng các phương pháp ban đầu hóa xoáy [7-8], hoặc ứng dụng phương pháp đồng hóa tổ hợp để nắm bắt được các nguồn bất định và tạo ra dự báo trung bình tổ hợp tốt nhất [2-3,5-6]. Đối với hướng nghiên cứu thứ hai liên quan đến việc ứng dụng các phương pháp thống kê để hiệu chỉnh dự báo quỹ đạo và cường độ bão ở Việt Nam 
[9], trong đó đã nghiên cứu và ứng dụng phương pháp lọc Kalman (KF) để hiệu chỉnh dự báo quỹ đạo và cường độ bão cho một số mô hình NWP toàn cầu. Khi áp dụng phương pháp KF để hiệu chỉnh các kết quả dự báo quỹ đạo và cường độ từ các mô hình NWP toàn cầu như mô hình GSM của Nhật Bản, GFS của Mỹ và IFS của ECMWF, các kết quả đánh giá dựa trên các chỉ số DPE, AT, CT cho dự báo quĩ đạo bão từ bộ số liệu của 24 cơn bão trong các mùa bão 2015-2019 cho thấy cả hai phương án thử nghiệm ứng dụng KF đều làm giảm sai số trong dự báo quỹ đạo. Điểm quan trọng của thử nghiệm này có thấy việc cập nhật những sai số quỹ đạo trong quá trình dự báo liên tục của các phiên dự báo là cần thiết.

Trong các nghiên cứu gần đây trên thế giới liên quan đến hướng tiếp cận thứ hai, quá trình hậu xử lý dự báo quỹ đạo bão từ các kết quả dự báo tổ hợp được thực hiện thống qua việc xem xét đến sai số dự báo thời gian ngắn (Short Lead Time-SLT) hoặc độ phân tán của thông tin dự báo từ các lần chạy hiện tại của mô hình hơn là việc chạy lại số liệu lịch sử. Ý tưởng chủ đạo của phương pháp là dịch chuyển một cách đơn giản dự báo quỹ đạo bão trong thời hạn dài (Long Lead Time-LLT) để khớp với các vị trí dự báo của mô hình trong thời gian ngắn (6-12 giờ) đối với vị trí dự báo mới nhất trước khi tiến hành tổ hợp [10-11]. Việc thực hiện phân tích chi tiết mối quan hệ giữa độ tán của quỹ đạo dự báo bão từ 5 mô hình động lực và sai số trung bình tổ hợp ở khu vực Tây Bắc Thái Bình Dương cho thấy nếu các dự báo viên luôn có thể chọn được dự báo tốt nhất từ các mô hình thành phần thì sai số dự báo sẽ giảm rất lớn [11-13]. Vấn đề đặt ra là không có công cụ nào sẵn có và cho phép dự báo viên có thể lựa chọn được các mô hình tốt nhất. Trung tâm cảnh báo bão của hải quân Hoa Kỳ (JTWC) đã áp dụng một hệ thống được thiết kế nhằm loại bỏ sai số dự báo quỹ đạo bão thời hạn 72 giờ từ các thành phần tổ hợp thông qua việc nhận dạng các sai số hệ thống trong mô hình NWP [14-16]. Tuy nhiên, đánh giá nghiệp vụ trong 5 năm cho thấy các dự báo viên không thể tạo ra một tổ hợp có lựa chọn để cung cấp ổn định so với phương pháp tổ hợp không có lựa chọn. Một kỹ thuật khách quan và tự động cho việc tổ hợp quỹ đạo (có lựa chọn hay không có lựa chọn) là một sự lựa chọn tốt hơn cho bài toán nghiệp vụ [17]. Một số tác giả đã thực hiện phương pháp để nâng cao chất lượng dự báo vị trí tổ hợp không có trọng số cho các thời hạn 96, 108, 120 giờ trên khu vực Tây Bắc Thái Bình Dương bằng cách sử dụng một hệ số có trọng số cho mỗi mô hình tỉ lệ nghịch với vị trí ở thời hạn 60,66 và 72 giờ của mô hình đó tương ứng với vị trí của 11 thành phần tổ hợp. Kết quả cho thấy kỹ năng dự báo tăng lên từ $5 \%$ đến $10 \%$ [18].

Các đánh giá về việc áp dụng dự báo tổ hợp trong dự báo quỹ đạo bão đều chỉ ra rằng trung bình tổ hợp (EM) cho kết quả tốt hơn so với mô hình tất định trong LLT và cho phép đưa ra được các thông tin dự báo xác suất hữu ích [19]. Tuy nhiên, một vấn đề còn tồn tại là liệu thông tin sai số trong thời hạn dự báo ngắn của các thành phần tổ hợp có thể dự báo quỹ đạo bão tốt hơn EM hay không. Do đó, một kỹ thuật trung bình tổ hợp có chọn lựa thành phần tổ hợp được đề xuất, kỹ thuật này có sự khác biệt so với phương pháp mà Elsberry đề xuất năm 2008 ở hai khía cạnh: i) kỹ thuật trung bình tổ hợp có chọn lựa thành phần tổ hợp này phụ thuộc vào hệ thống tổ hợp vốn cung cấp nhiều thành phần tổ hợp hơn so với 11 thành phần tổ hợp Elsberry sử dụng và ii) kỹ thuật trung bình tổ hợp có chọn lựa này phụ thuộc vào sai số vị trí trong thời hạn dự báo ngắn nhiều hơn là độ lệch hay độ tán của vị trí trong thời hạn dự báo ngắn của Elsberry. Do đó, kỹ thuật mới này đòi hỏi phải tính toán đến những quan trắc mới nhất. Với vấn đề nghiên cứu mang tính cập nhật đã nêu, bài báo sẽ trình bày phương pháp trung bình có lựa chọn cho dự báo quỹ đạo bão dựa trên sai số của các thành phần hệ thống dự báo tổ hợp tại các thời hạn dự báo ngắn (SLT, 12 giờ) [20]. Một số thử nghiệm ban đầu được áp dụng trong một trường hợp dự báo từ các sản phẩm tổ hợp từ ECMWF trên khu vực Biển Đông. 


\section{Phương pháp và tập số liệu nghiên cứu}

\subsection{Phưong pháp trung bình có trọng số theo thành phần tổ hợp}

Kỹ thuật trung bình tổ hợp có lựa chọn trong nghiên cứu [20] sử dụng thông tin về sai số vị trí thời hạn dự báo ngắn từ mỗi thành phần tổ hợp để tạo ra một giá trị trung bình để dự báo quỹ đạo thời hạn dài hơn. Do đó tổ hợp được hiểu là một phương pháp tổng hợp dựa trên sai sô SLT với lý thuyết là các thành phần có sai số thấp ở SLT sẽ có sai số dự báo LLT nhỏ hơn. Trong nghiệp vụ, các sản phẩm tổ hợp thường đến được với các dự báo viên với độ trễ thời gian nhất định, điều này xuất phát từ các nguyên nhân như năng lực tính toán và truyền tải số liệu. Đối với các hệ thống tổ hợp, thời gian trễ thường là hơn 6 giờ. Ví dụ, sản phẩm dự báo của phiên dự báo theo giờ quốc tế 00UTC sẽ đến được với dự báo viên lúc 06UTC hoặc thậm chí muộn hơn. Độ trễ này cho phép các dự báo viên có thể đánh giá kỹ năng dự báo trong SLT, từ đó ước lượng độ tin cậy trong dự báo LLT của các thành phần tổ hợp này. Trong nghiên cứu [20] thời hạn dự báo ngắn được xác định là 12 giờ bởi các lý do: i) các hệ thống tổ hợp sử dụng đều chạy tại 02 phiên $00 \mathrm{UTC}$ và $12 \mathrm{UTC}$ và các sản phẩm tổ hợp nghiệp vụ luôn có độ trễ hơn 6 giờ và ii) các sản phẩm từ hệ thống tổ hợp chỉ được cung cấp trong khoảng thời gian 12 giờ. Trung bình tổ hợp cuối cùng được xác định bởi các bước sau:

Sai số vị trí SLT tại 12 giờ được tính toán cho các dự báo quỹ đạo từ tất cả các thành phần tổ hợp liên quan đến quan trắc;

$>$ Sai số vị trí SLT trung bình của tất cả thành phần tổ hợp được tính toán;

$>$ Các thành phần có sai số nhỏ hơn sai số SLT trung bình sẽ được lựa chọn;

$>2$ giá trị trung bình tổ hợp sẽ được tính toán đơn giản bằng cách lấy trung bình cộng các thành phần được lựa chọn và tính trọng số các thành phần được lựa chọn với hệ số tî lệ nghịch với các thành phần tương ứng;

$>$ Sai số trung bình và trọng số để tính toán quỹ đạo trung bình tổ hợp sẽ được điều chỉnh để khớp với vị trí SLT với các số liệu quan trắc mới nhất. Quỹ đạo được điều chỉnh cuối cùng ký hiệu là trung bình của các thành phần tổ hợp có lựa chọn (SEAV), trung bình có trọng số của các thành phần tổ hợp có lựa chọn (SEWE).

Hình 1 minh họa trường hợp tồn tại 3 thành phần tổ hợp (kí hiệu tương ứng là $\mathrm{m}_{1}, \mathrm{~m}_{2}$, $\mathrm{m}_{3}$ ) được lựa chọn để xác định dự báo tổ hợp trọng số cuối cùng do đáp ứng chỉ tiêu sai số vị trí SLT nhỏ hơn so với sai số SLT trung bình của tất cả thành phần. Trong trường hợp này, dự báo LLT của 3 thành phần này sẽ được sử dụng để xác định dự báo SEAV hoặc dự báo SEWE cuối cùng.

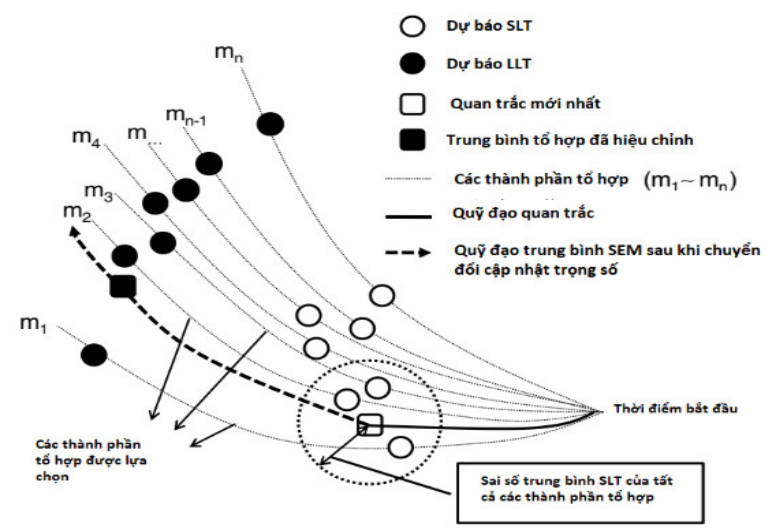

Hình 1. Sơ đồ kỹ thuật trung bình tổ hợp có lựa chọn trong đó bán kính của vòng tròn gạch ngang cho biết giá trị sai số SLT trung bình của tất cả thành phần tổ hợp. Hình vuông tại tâm vòng tròn là vị trí quan trắc mới nhất của cơn bão. Trong hình này, chỉ có 3 thành phần $(\mathrm{m} 1, \mathrm{~m} 2, \mathrm{~m} 3)$ có sai số SLT nhỏ hơn sai số SLT trung bình được chọn để xác định vị trí và quỹ đạo trung bình tổ hợp LLT (hình vuông đen và đường đứt đoạn). Nguồn: Qi và cộng sự năm 2014 [21]. 
Sơ đồ trọng số được thiết kế để xác định trọng số dự báo quỹ đạo LLT bởi hệ số tỉ lệ nghịch với các sai số SLT tương ứng, được đặt tên là $e_{1}, e_{2}, e_{3}$. Khi đó các trọng số được tính toán theo phương trình (1-3).

$$
\begin{aligned}
& w_{1}=\frac{1}{e_{1}} ; w_{2}=\frac{1}{e_{2}} w_{3}=\frac{1}{e_{3}} \\
& x=\left(w_{1}+w_{2}+w_{3}\right) \\
& W_{1}=\frac{w_{1}}{x}, W_{x}=\frac{w_{2}}{x}, W_{3}=\frac{w_{3}}{x}
\end{aligned}
$$

Trong đó $W_{1}, W_{2}, W_{3}$ là các hệ số trọng số của các thành phần được chọn. Một số trường hợp tồn tại được chọn không có dự báo LLT, đặc biệt là khi xoáy thuận nhiệt đới bước vào giai đoạn suy yếu. Trong các trường hợp này, một quy trình lựa chọn trọng số sẽ được thực hiện với các thành phần còn lại và tuân theo các phương trình từ (1-3). Trong phương pháp này, [20] đề xuất cần ít nhất 2 thành phần tổ hợp cho tất cả các thời hạn dự báo. Lưu ý rằng quá trình tính toán xác định các thành phần sát nhất với quan trắc ở các ốp dự báo trước dựa trên sai số dự báo quỹ đạo DPE (Direct Possition Error). Đây là khoảng cách giữa vị trí tâm bão quan trắc (trong điều kiện nghiệp vụ chính là tâm phân tích xoáy thuận nhiệt đới từ dữ liệu vệ tinh, quan trắc gió bề mặt biển).

Như vậy, công thức của phương pháp [20] sẽ được mở rộng với $N$ thành phần tổ hợp, thành phần thứ $i$ có sai số khoảng cách DPE (kí hiệu là $e_{i}$ ) ở hạn SLT đáp ứng, sẽ có dạng như sau:

$$
\begin{aligned}
& w_{i}=\frac{1}{e_{i}} \\
& x=\sum_{1}^{N} w_{i} \\
& W_{i}=\frac{w_{i}}{x}
\end{aligned}
$$

Các sai số đáp ứng ở STL liên quan đến chính mẫu thống kê của từng hệ thống dự báo tổ hợp. Ví dụ ở hạn 6-12 giờ, sai số quỹ đạo đối với trung bình tổ hợp của ECMWF khoảng 40$60 \mathrm{~km}$, hạn 12-24 giờ ở khoảng 60-100km.

\subsection{Số liệu thử nghiệm}

Trong nghiên cứu sử dụng số liệu quỹ đạo bão chuẩn của Trung tâm Dự báo khí tượng thủy văn quốc gia. Cơn bão thử nghiệm được lựa chọn là bão số 12 với tên là Damrey, mã số quốc tế là 1723 . Sáng ngày $02 / 11 / 2017$, cơn ATNĐ có vị trí ở vùng biển phía Đông Bắc quần đảo Trường Sa đã mạnh lên thành bão, đây là cơn bão thứ 23 trên khu vực Tây Bắc Thái Bình Dương và là cơn bão số 12 hoạt động trên Biển Đông. Sau khi mạnh lên, bão số 12 tiếp tục di chuyển chủ yếu theo hướng Tây. Sáng ngày 04/11/2017, bão số 12 đã đổ bộ vào khu vực các tỉnh Phú Yên và Khánh Hòa, sau đó bão di chuyển theo hướng Tây Tây Nam, đi sang Tây Nguyên và suy yếu thành một vùng áp thấp trên khu vực phía Nam của Campuchia (Hình 2).

Đối với sản phẩm dự báo tổ hợp sẽ thử nghiệm trong bài báo, đây là hệ thống dự báo tổ hợp toàn cầu của ECMWF bao gồm 51 thành phần dự báo. Trung tâm Dự báo khí tượng thủy văn quốc gia đã bắt đầu mua số liệu dự báo toàn cầu cả sản phẩm tất định và tổ hợp từ Trung tâm dự báo thời tiết hạn vừa Châu Âu (ECMWF) từ cuối năm 2011 [21]. Từ năm 2014 có độ phân giải ngang xấp xỉ 28 km, năm 2020 giảm xuống còn 16 km. 


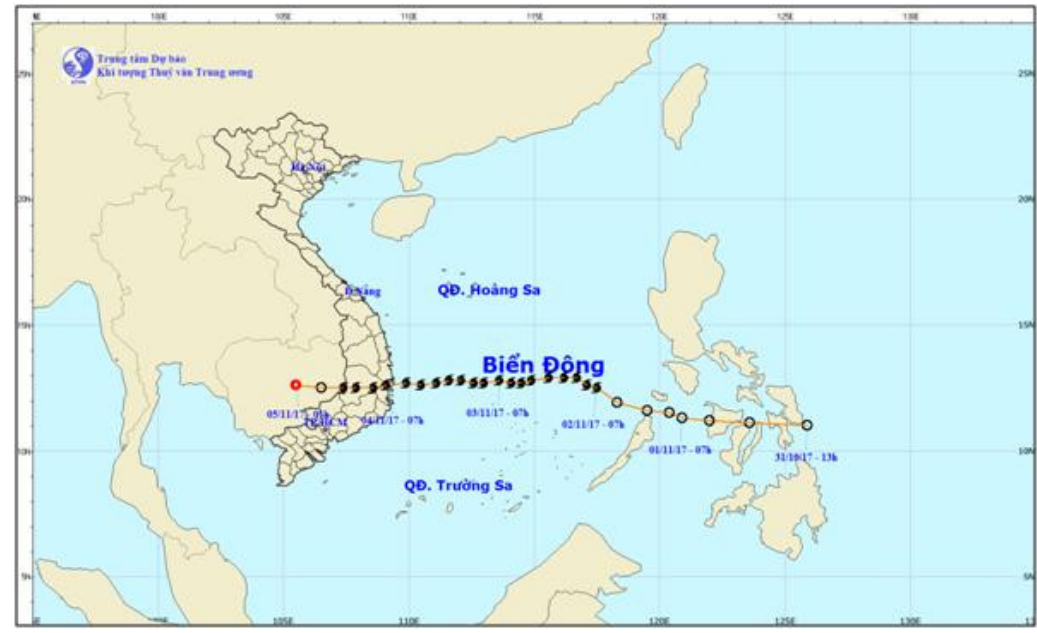

Hình 2. Quỹ đạo bão chuẩn của bão số 12-Damrey (1723).

\section{Kết quả}

Phương pháp được áp dụng với cơn bão số 12 (Damrey) từ phiên dự báo 00UTC ngày 01/11/2017 đến 00UTC ngày 02/11/2017. Như vậy có 03 phiên dự báo giữa 2 ngày lựa chọn này để tính toán được các thành phần có sai số phù hợp. Trong nghiên cứu áp dụng giá trị 40 $\mathrm{km}$ cho sai số hạn 6 giờ và $60 \mathrm{~km}$ cho hạn 12 giờ. Quỹ đạo của các dự báo từng thành phần tổ hợp được đưa ra trong hình 3.
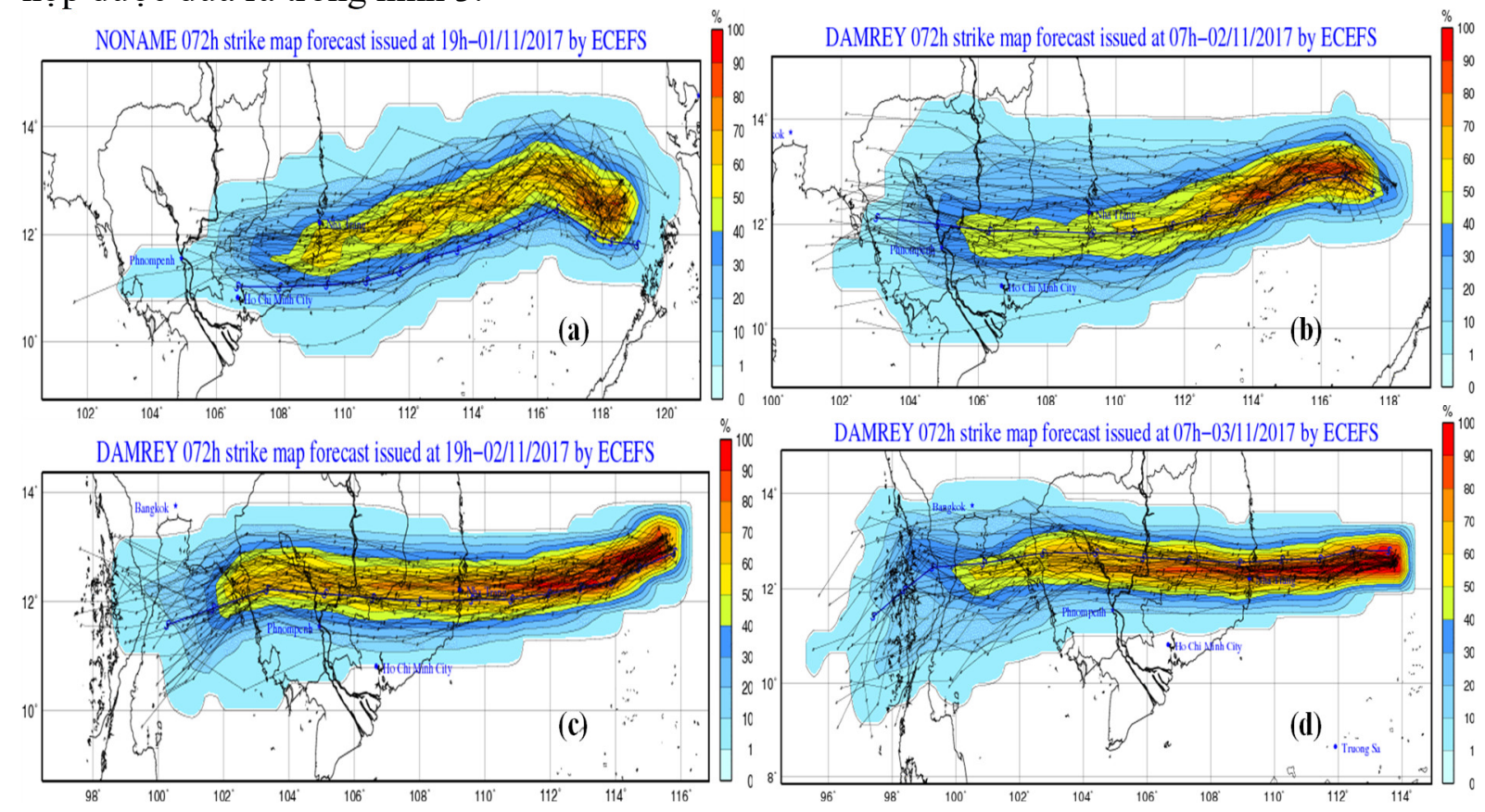

Hình 3. Dự báo quỹ đạo cơn bão Damrey từ hệ thống tổ hợp ECMWF từ phiên 12UTC ngày 01/11/2017 đến 00UTC ngày 03/11/2017.

Bảng 1 là sai số quỹ đạo DPE tại các phiên từ 00UTC ngày 01/11/2017 đến 00UTC ngày 02/11/2017 của từng thành phần tổ hợp xác định so với các vị trí tâm bão phân tích tức thời (được xem như là quỹ đạo bão chuẩn). Thứ tự các thành phần dự báo được minh họa sắp xếp lại theo sai số quỹ đạo DPE tương ứng tự thấp đến cao. Số lượng các thành phần $(\mathrm{N})$ của từng phiên dự báo được đưa ra trong bảng 2 . Các hệ số trọng số ứng với từng thành phầm được minh họa trong hình 4 cho phiên dự báo 00UTC ngày 01/11/2017. 
Bảng 1. Sai số khoảng cách quỹ đạo tại từng phiên dự báo được áp dụng trong việc tìm số các thành phần sai số tối ưu và tỉ lệ số thành phần có các sai số theo các hạn ngắn 6 giờ và 12 giờ (kí hiệu DPE06 giờ và DPE12 giờ) nằm trong ngưỡng lựa chọn $(40 \mathrm{~km}$ và $60 \mathrm{~km})$. Kí hiệu thành phần $(\mathrm{TP})$ thứ 0 là mem00. Tùy vào sai số của từng thành phần mà các thứ tự (TT) sai số đã được xắp xếp lại từ nhỏ đến lớn.

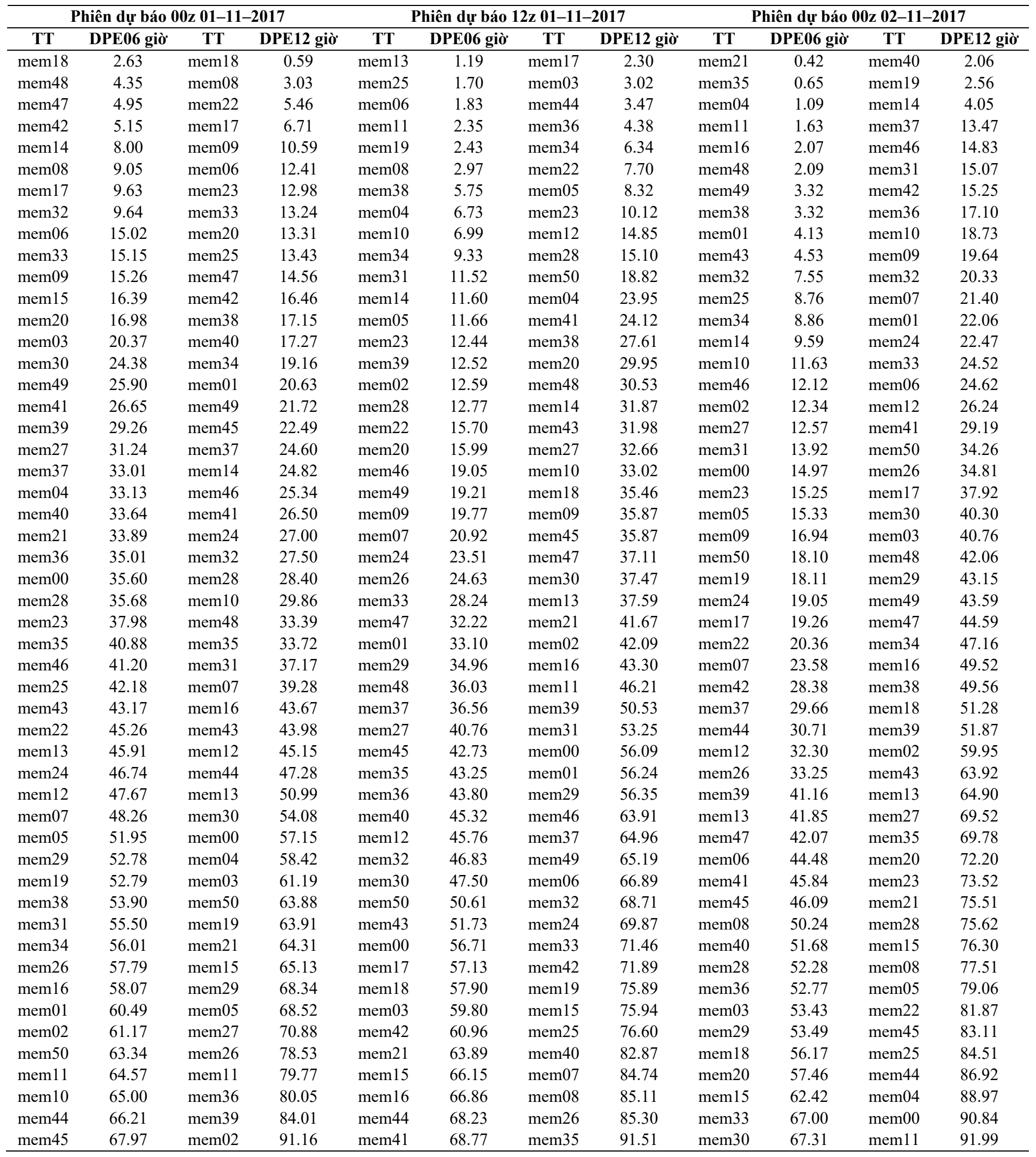


Bảng 2. Sai số khoảng cách tại từng phiên áp dụng trong việc tìm các thành phần sai số tối ưu.

\begin{tabular}{ccc}
\hline Phiên dự báo & $\begin{array}{c}\text { Số thành phần đạt }<\text { 40km, hạn } \mathbf{6} \\
\text { giờ }\end{array}$ & $\begin{array}{c}\text { Số thành phần đạt < 60km, hạn 12 } \\
\text { giờ }\end{array}$ \\
\hline 00UTC 01-11-2017 & 27 & 37 \\
12UTC 01-11-2017 & 31 & 34 \\
00UTC 02-11-2017 & 34 & 32 \\
\hline
\end{tabular}

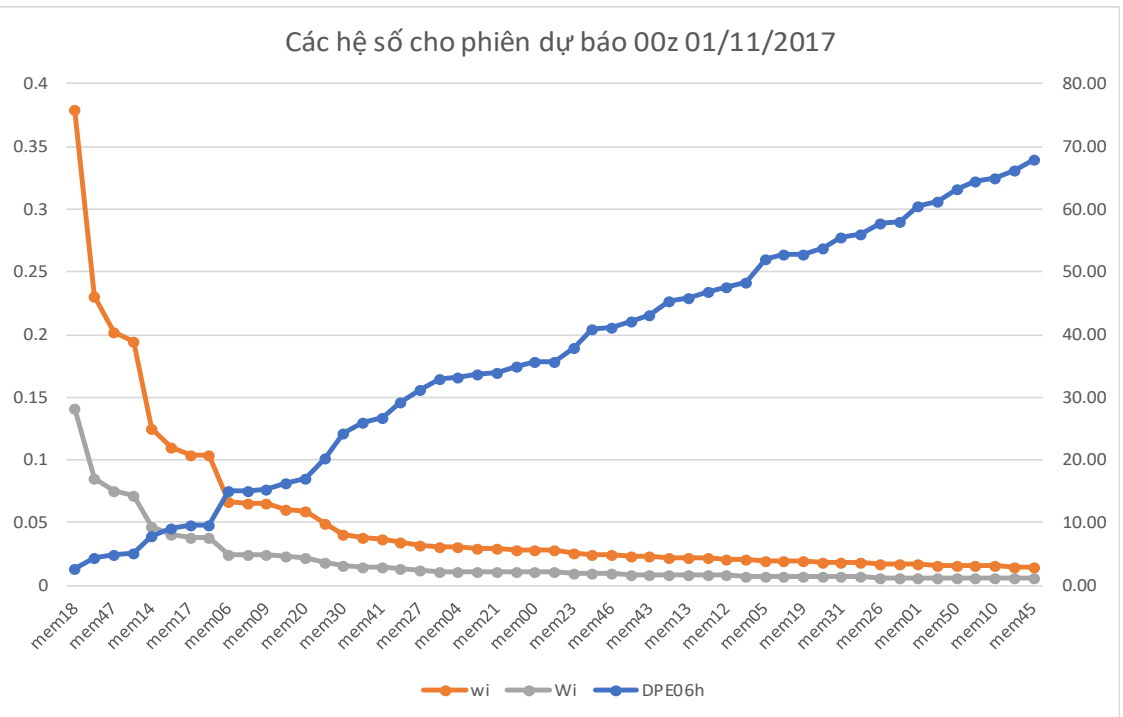

Hình 4. Minh họa các chỉ số trọng số của từng thành phần tổ hợp ứng với phiên dự báo 00UTC ngày $01 / 11 / 2017$.

DAMREY 072h strike map forecast issued at 19h-02/11/2017 by ECEFS

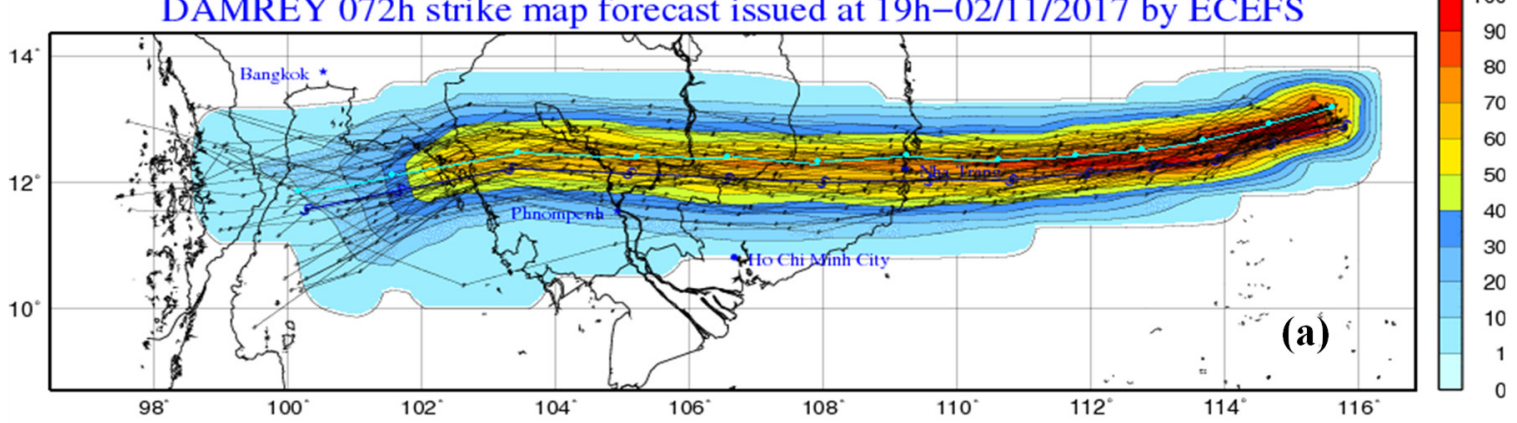

DAMREY 072h strike map forecast issued at 07h-03/11/2017 by ECEFS

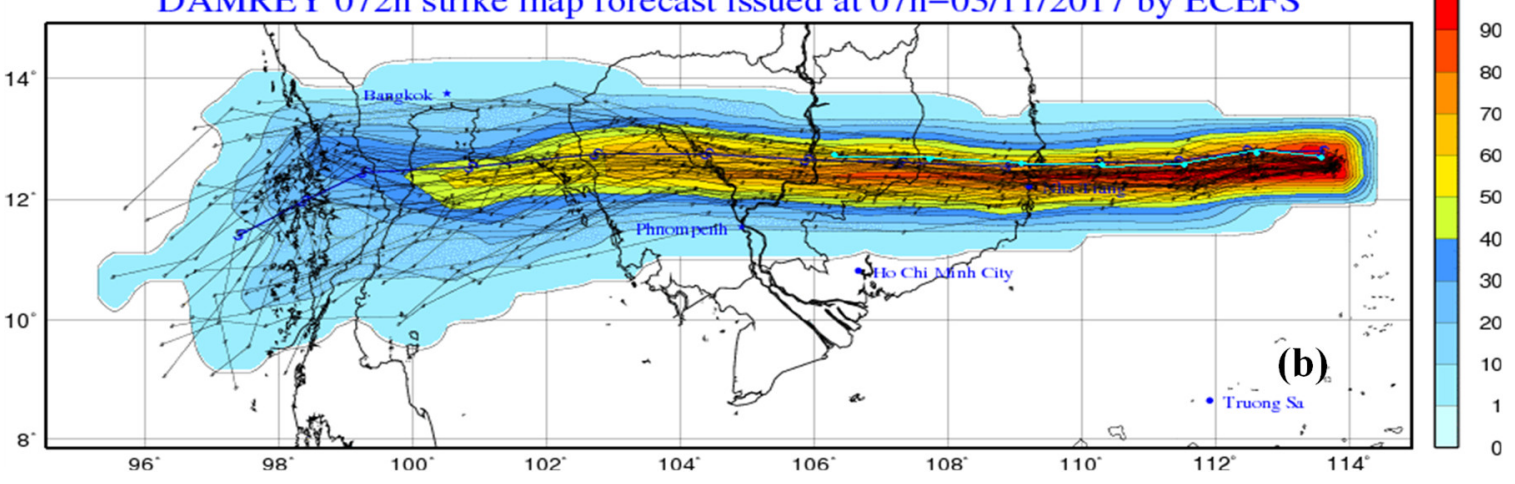

Hình 5. Quỹ đạo hiệu chỉnh (đường màu xanh chấm sáng) theo việc lựa chọn các thành phần tổ hợp có sai số thấp nhất với các phiên phân tích gần nhất. Đường màu xanh đậm tối kèm kí hiệu xoáy thuận là quỹ đạo trung bình tổ hợp chưa hiệu chỉnh. Hình a: phiên dự báo 12UTC ngày 02/11/2017, hình b: phiên dự báo 00UTC ngày 03/11/2017. 
Kết quả dự báo trung bình tổ hợp trước khi hiệu chỉnh, ở phiên dự báo 12UTC ngày 02/11/2017 và một số phiên dự báo trước đó (hình 3 ) cho thấy xu thế dự báo thấp hơn so với thực tế. Dự báo tổ hợp khá thống nhất, thể hiện ở độ chụm của các quỹ đạo từng thành phần và mức độ tán nhỏ của dự báo. Tuy nhiên ở các phiên ngày $01 / 11$ và $02 / 11$, quỹ đạo bão vẫn có xu hướng di chuyển theo hướng Tây Tây Bắc trước khi đi về phía Tây và đổ bộ vào khu vực Nam Trung Bộ. Trường hợp nghiên cứu này cho thấy độ tán nhỏ có thể dẫn tới việc xác định được không rõ được các thành phần có sai số tốt nhất tách biệt hẳn so với các thành phần còn lại và hệ quả việc hiểu chỉnh sẽ ít có tác dụng. Trong hình 5 là kết quả tính toán quỹ đạo trung bình trọng số ở hai phiên 12 UTC ngày $02 / 11 / 2017$ và $00 U T C$ ngày $03 / 11 / 2017$. Ơ phiên dự báo 12UTC ngày 02/11/2017, việc hiệu chỉnh cho kết quả giảm sai số DPE khoảng $15 \%$ cho hạn dự báo 24 giờ và cho khu vực đổ bộ hợp lý hơn so với dự báo ban đầu dự báo đổ bộ vào sát khu vực Nha Trang. Ở phiên dự báo 00UTC ngày 03/11/2017, sự khác biệt giữa hai quỹ đạo trung bình tổ hợp trước và sau hiệu chỉnh không rõ như phiên 12UTC ngày 02/11/2017 liên quan đến việc sau phiên 12UTC ngày 01/11/2017, quỹ đạo bão được dự báo khá thống nhất đi vào khu vực Nam Trung Bộ, ít tồn tại các thành phần có dự báo đi lên phía Tây Bắc.

\section{Kết luận}

Nghiên cứu đã giới thiệu phương pháp trung bình có lựa chọn cho dự báo quỹ đạo bão dựa trên sai số của các thành phần hệ thống dự báo tổ hợp tại các thời hạn dự báo ngắn (6-12 giờ), đề xuất bởi Qi và cộng sự năm 2014 và đã thử nghiệm tính toán, đánh giá cụ thể đối với trường hợp dự báo cơn bão Damrey năm 2017 từ các sản phẩm tổ hợp gồm 51 thành phần dự báo của ECMWF. Kết quả cho thấy khả năng hiệu chỉnh rõ rệt của phương pháp lựa chọn các thành phần tổ hợp với sai số trong ngưỡng xem xét ở các hạn dự báo ngắn hạn. Đối với các quá trình thay đồi quỹ đạo, phương pháp có thể ít cải thiện được nhiều sai số dự báo so với quỹ đạo trung bình tổ hợp, tuy nhiên ở các thời hạn ngắn 24-48 giờ và khi trường hợp các cơn bão có cường độ mạnh và quỹ đạo ổn định, phương pháp trung bình trọng số sẽ giảm thiểu được sai số dự báo quỹ đạo trung bình tổ hợp. Các nghiên cứu tiếp theo sẽ được thực hiện với mẫu thử nghiệm dài hơn để đánh giá được cụ thể việc áp dụng phương pháp này cũng như khả năng ứng dụng trong nghiệp vụ dự báo vị trí bão đổ bộ tại Việt Nam.

Đóng góp của tác giả: Xây dựng ý tưởng nghiên cứu: T.Q.N., T.T.T; Lựa chọn phương pháp nghiên cứu: T.Q.N., T.T.T.; Xử lý số liệu: T.Q.N., T.T.T; Viết bản thảo bài báo: T.Q.N; Chỉnh sửa bài báo: T.Q.N.

Lời cam đoan: Tập thể tác giả cam đoan bài báo này là công trình nghiên cứu của tập thể tác giả, chưa được công bố ở đâu, không được sao chép từ những nghiên cứu trước đây; không có sự tranh chấp lợi ích trong nhóm tác giả.

\section{Tài liệu tham khảo}

1. Tiến, T.T. và cs. Xây dựng công nghệ dự báo liên hoàn bão, nước dâng và sóng ở Việt Nam bằng mô hình số với thời gian dự báo trước 3 ngày. Báo cáo tổng kêt Đề tài NCKH cấp Nhà nước thuộc Chương trình "Khoa học và công nghệ phục vụ phòng tránh thiên tai, bảo vệ môi trường và sử dụng hợp lý tài nguyên thiên nhiên". Mã số: KC.08.05/06-10, 2010.

2. Tiến, T.T.; Thanh, C.; Phượng, N.T. Dự báo cường độ bão bằng mô hình WRF hạn 5 ngày trên khu vực biển Đông. Tạp chi Khoa hoc ĐHQGHN 2012, T28(3S), 155-160.

3. Tiến, T.T.; Thanh, C.; Trường, N.M.; Hiền, T.D. Đánh giá bước đầu khả năng dự báo quỹ đạo bão bằng mô hình MM5 kết hợp với cài xoáy nhân tạo và cập nhật số liệu địa phương khu vực Việt Nam. Tạp chí Khoa học ĐHQGHN 2009, T25(1S), 109-114. 
4. Cường, H.Đ. Nghiên cứu ứng dụng mô hình WRF phục vụ dự báo thời tiết và bão ở Việt Nam. Báo cáo tổng kết đề tài NCKH cấp Bộ, 2011.

5. Hòa, V.V. và cs. Nghiên cứu ứng dụng dự báo tổ hợp cho một số trường dự báo bão. Báo cáo tổng kết đề tài NCKH cấp Bộ, 2008.

6. Hòa, V.V. và cs. Nghiên cứu phát triển hệ thống dự báo tổ hợp thời tiết hạn ngắn cho khu vực Việt Nam. Báo cáo tổng kết đề tài NCKH cấp Bộ, 2012.

7. Tân, P.V.; Hải, B.H. Ban đầu hóa xoáy ba chiều cho mô hình MM5 và ứng dụng trong dự báo quỹ đạo bão. Tạp chí Khí tương Thủy văn 2004, 526, 14-25.

8. Tân, P.V.; Dũng, N.L. Thử nghiệm ứng dụng hệ thống WRF-VAR kết hợp với sơ đồ ban đầu hóa xoáy dự báo quĩ đạo bão trên biển Đông. Tạp chí Khí tuợng Thủy văn 2009, 583, 1-9.

9. Thái, T.H.; Hòa, V.V. Úng dụng lọc Kalman trong hậu xử lý kết quả dự báo quỹ đạo và cường độ bão cho một số mô hình dự báo số trị toàn cầu. Tạp chi Khí tượng Thủy văn 2019, EME2, 120-129.

10. Tsai, H.C.; Russell, L.E. Detection of tropical cyclone track changes from the ECMWF ensemble prediction system. Geophys. Res. Lett. 2013, 40, 797-801. https://doi.org/10.1002/grl.50172.

11. Goerss, J.S.; Sampson, C.R.; Gross, J.M. A history of western North Pacific tropical cyclone track forecast skill. Weather Forecasting 2004, 19, 633-638. https://doi.org/10.1175/1520-0434(2004)019<0633:AHOWNP>2.0.CO;2.

12. Sampson, C.R.; Goerss J.S.; Weber, H.C. Operational performance of a new barotropic model (WBAR) in the Western North Pacific Basin. Weather Forecasting 2006, 21, 656-662. https://doi.org/10.1175/WAF939.1.

13. Elsberry, R.L.; Carr, L.E. Consensus of dynamical tropical cyclone track forecasts: Errors versus spread. Mon. Weather Rev. 2000, 128, 4131-4138. https://doi.org/10.1175/1520-0493(2000)129<4131:CODTCT>2.0.CO;2.

14. Carr, L.E., Elsberry, R.L. Dynamical tropical cyclone track forecast errors. Part I: Tropical region error sources. Weather Forecasting 2000, 15, 641-661.

15. Carr, L.E.; Elsberry, R.L. Dynamical tropical cyclone track forecast errors. Part II: Midlatitude circulation influences. Weather Forecasting 2000, 15, 662-681.

16. Carr, L.E.; Elsberry, R.L; Peak, J.E. Beta test of the systematic approach expert system prototype as a tropical cyclone track forecasting aid. Weather Forecasting 2001, $16, \quad 355-368 . \quad \mathrm{https}: / /$ doi.org/10.1175/15200434(2001)016<0355:BTOTSA $>2.0$. CO;2.

17. Sampson, C.R.; Knaff J.A.; Fukada E.M. Operational evaluation of a selective consensus in the Western North Pacific Basin. Weather Forecasting 2007, 22, 671675. https://doi.org/10.1175/WAF991.1.

18. Elsberry, R.L.; Hughes, J.R.; Boothe, M.A. Weighted position and motion vector consensus of tropical cyclone track prediction in the western North Pacific. Mon. Wea. Rea. 2008, 136, 2478-2487. https://doi.org/10.1175/2007MWR2262.1.

19. Hamill, T.M.; Whitaker, J.S.; Fiorino, M.; Benjamin, S.G. Global ensemble predictions of 2009's tropical cyclones initialized with an ensemble Kalman filter. Mon. Weather Rev. 2011, 139, 668-688. https://doi.org/10.1175/2010MWR3456.1.

20. Qi, L.B.; Yu H.; Chen, P.Y. Selective ensemble-mean technique for tropical cyclone track forecast by using ensemble prediction systems. Q. J. R. Meteorol. Soc. 2014, $140,805-813$.

21. Hòa, V.V. và cs. Nghiên cứu ứng dụng số liệu dự báo của Trung tâm Dự báo thời tiết hạn vừa Châu Âu để nâng cao chất lượng dự báo hạn tháng và hạn mùa cho khu vực Việt Nam. Báo cáo tổng kết đề tài NCKH cấp Bộ, 2016, 129tr. 


\title{
On the post-processing method of tropical cyclone's track forecast from ensemble prediction system by using short lead time track error information
}

\section{Tran Quang Nang ${ }^{*}$, Tran Tan Tien ${ }^{2}$}

${ }^{1}$ National Center for Hydrometeorological Forecasting; trannang030984@gmail.com;

${ }^{2} \mathrm{Ha}$ Noi University of Science; tientt49@gmail.com

\begin{abstract}
This article presents the method of post-processing tropical cyclone's track forecast from the ensemble prediction system by using short lead time track error information. Generally, the tropical cyclone track forecast is produced from the ensemble mean of the ensemble members. However, when conducting the verification of the position errors at a short lead time (6-12 hours) of the positions analyzed from satellites, sea surface wind (best-track in real-time), there will be several members have smaller errors than the annual-mean error of the ensemble means. Therefore, the selected ensemble mean approach will be a method to allow reduce the forecast errors. This article will review and present the selected ensemble method for tropical cyclone track forecasts based on the errors of the members of the ensemble forecasting system (EPS) at a short lead time (6-12 hours) which was proposed by Qi et al. 2014. Some results were applied in a case of Typhoon Damrey in the year 2017 using the ensemble products of 51 members of the European Centre for Medium-Range Weather Forecasts (ECMWF).
\end{abstract}

Keywords: Ensemble forecast; Ensemble forecast for tropical cyclone's track; Selective ensemble member. 